\title{
Measuring the sustainability of policy scenarios: Emergy-based strategic environmental assessment of the Chinese paper industry
}

\author{
Jing-Ming Ren ${ }^{\mathrm{a}, \mathrm{b}}$, Lei Zhang ${ }^{\mathrm{c}, *}$, Ru-song Wang ${ }^{\mathrm{a}}$ \\ ${ }^{a}$ Research Center for Eco-Environmental Sciences, Chinese Academy of Sciences, Beijing 100085, China \\ ${ }^{\mathrm{b}}$ Appraisal Center for Environment E Engineering, Ministry of Environmental Protection of the People's Republic of China, Beijing 100012, China \\ ' School of Environment and Natural Resources, Renmin University of China, Beijing 100872, China
}

\section{A R T I C L E I N F O}

\section{Article history:}

Received 26 September 2009

Received in revised form 16 April 2010

Accepted 20 April 2010

Available online 10 May 2010

\section{Keywords:}

Sustainability

Emergy index

SEA

Chinese paper policy

\begin{abstract}
A B S T R A C T
Recent years have seen increasing demand for wider application of strategic environmental assessment (SEA), especially SEA of major policies, as a powerful instrument to safeguard the environment during the rapid industrialization and urbanization in China. Debates on SEA are concentrated on its feasibility and effective implementation in practice. This study applies Emergy analysis within the framework of social-economic-natural complex eco-system theory to overcome the limitations of methods used for assessing regional sustainability so far. This established model is tested in the case of Chinese paper industry to assess the sustainability of 5 policy scenarios. The results show that Emergy-based Indices (EbI) are more effective to measure the sustainability of industry complex ecosystem, thus EbI approach is very useful in SEAs on policy scenarios of a given complex ecosystem.
\end{abstract}

(c) 2010 Elsevier B.V. All rights reserved.

\section{Introduction}

The adoption of the 'circular economy' by the Chinese government shows strong political determination to shift from 'fast and well' development to 'well and fast' development in scientific approaches, which respects the laws of nature and recognizes the need for coordinated development. The realization of this shift depends largely on proper assessment, especially environmental assessment next to social economic assessment of strategic decisions before they are implemented. The concept of circular economy requires looking at industry as just one of the components of the ecological system. Human society is a kind of social-economic-natural complex ecosystem (SENCE) that is dominated by human performance, supported by natural environment, motivated by resource flowing and organized by social system (Wang, 2003). Industry is a typical complex ecosystem from the perspective of SENCE. The sustainability of such industrial complex eco-systems is crucial for the overall sustainability of the economy and society. Thus, comprehensive assessment of the sustainability of an industry needs a comprehensive theoretical framework and overarching methodologies, which integrate the relations (temporal relation, spatial relation, quantitative relation, structural relation and ordinal relation) and the flows in a complex ecosystem, including

\footnotetext{
* Corresponding author. Tel.: +8610 82502990; fax: +8610 62511645 . E-mail address: lei.leizhang@gmail.com (L. Zhang).
}

material flow, energy flow, capital flow, information flow and population flow.

Environmental impact assessment (EIA) at the project level has been widely applied in many countries since early 1970s as an effective tool to minimize negative environmental impacts of projects (Appiah, 2001; Momtaz, 2002; Magelli et al., 2009; Wang et al., 2003). The failure of project-based EIA in dealing with accumulative effects and limited alternatives actually lead to the rapid development of the strategic environmental assessment (SEA) - any environmental assessment above project level around the world. SEA was defined as a systematic process in which environmental, economic and social consequences of proposed policies, plans and programs are evaluated at the earliest appropriate stage of decision-making (Say and Yucel, 2006). Since the beginning of 21st century, marked with the EU SEA Directive (The Strategic Environmental Assessment Directive, 2001/42/EC), the expansion and institutionalization of SEA have been observed from the developed to the developing countries. While the potential of SEA on improving strategic decision makings has been well recognized, in practice, SEA on policy level has met, to various extents, legal, institutional, financial and technical barriers. In addition, there is no single agreement on the legal status and the scope of SEA. To focus only on environmental impacts or to be integrated into assessment of sustainable development is still the focus of the debates.

EIA has been one of the core environmental policies in China. The EIA law of 2003 can be seen as a milestone on the development of both China's environmental protection and the enforcement of 
environmental impact assessment. It will have tremendous influence on environmental protection, China's basic national policy, and the sustainable development strategy (Huang and Jennifer, 2005; Zhu and Ru, 2008). To safeguard the national strategy towards development in scientific approaches, China is in need of SEA to integrate environmental considerations, next to social and economic interests, in all kinds of policies. Huang and Jennifer conclude from their case on Three Gorges Dam Project that it is necessary for the government to seek a SEA covering not only environmental impacts, but also archaeological and cultural heritage for decision-making purposes (Huang and Jennifer, 2005). The application of decision-making level SEA should be encouraged without delay in China.

Methodologically, SEA can learn from the assessment on regional sustainable development. Three approaches are often used to assess regional sustainable development (Yang and Cai, 2000). First, material flow is used as the measurement unit, i.e. the material flow accounting system (MFA); second, currency is used as the measurement unit, i.e. the system of integrated environmental and economic accounting (SEEA); third, energy is used as the measurement unit, i.e. the energy accounting system (EbA). Experiences with these three approaches show that each has its advantages and disadvantages. With MFA, the actual impacts on environment and resources are not reflected, nor the impacts on the economic development and social welfare. Although SEEA takes environmental cost and benefit into the national economic accounting system by transforming them into monetary terms, it is not always convincing to what extent the actual value of the environment is calculated. Compared with the former two, EbA overcomes the aforementioned limitations by transforming all kinds of processes and products of environmental and economic systems into energy in a dynamic model. EbA can be applied in different ways, depending on which energy is focused. Among these methods, Emergy analysis (EMA) is the most widely applied one (Cai, 2000). The characteristics of Emergy approach are: (1) very extensive applicability, energy is necessarily used for ecosystem processes, and Emergy becomes a good measure of equivalence for indicating the relations among various types of energy and material fluxes. (2) Emergy analysis may connect human consumption with natural ecosystems and include all the direct and indirect consumption of energy by humans. (3) Emergy analysis is a process-based dynamic approach (Hu et al., 2009). The strength of EMA lays in the fact that it is able to express different energies into one single unit, solar Emergy, so that quantitative analysis becomes possible (Odum, 1996; Hau and Bakshi, 2004; Li and Wang, 2009). In this way, Emergy can be used to measure the sustainability of a complex eco-system. This article takes the perspective of SENCE and applies modified EMA model and indices in the SEA on the Chinese paper industry policy scenarios.

\section{Modified Emergy-based indices for assessing industry complex ecosystem}

According to SENCE, the sustainability of a complex eco-system includes the sustainability of all its subsystems, namely natural, economic and social systems. In this context, environmental impact assessment is integrated into the assessment on the sustainability of a complex eco-system. This requires the establishment of indices that reflect all these aspects of the ecosystem.

Various Emergy sustainable indices (ESIs), the ratio of Emergy yield ratio (EYR) to environmental loading ratio (ELR), are generated based on Emergy theory. The first set of indices established by Brown and Ulgiati in 1997 have contributed significantly to the research on sustainable development (Brown and Ulgiati, 1997). Many researchers have applied these indices in the assessment of sustainability of regions of different scales and with different economic behaviors (Li, 2000; Li et al., 2001, 2003a,b; Sui et al., 1999; Sui and Lan, 2001; Yan and Odum, 1998; Zhang et al., 1998). Over the years, ESIs have been constantly challenged and improved to solve the following problems:

Although from an ecological perspective, wastes or energy discharged from a system are "wastes" only because the current knowledge and technologies are not able to turn the "wastes" into resources, not all the outputs of a system are positive. It is not always the case that the higher Emergy yield ratio (EYR) is, the more beneficial to the sustainability of the system. In addition, as far as enterprises are concerned, both renewable resources and non-renewable resources cost money. Therefore, over consumption of renewable resources is not always a rational choice from both economic and environmental perspectives. The same Emergy output can mean different impacts on the development of a complex ecosystem because the market, culture and ethic also influence the Emergy transformation in the process of trade exchange (Lan et al., 1998).

Environmental loading ratio (ELR) refers to the ratio of Emergy input of non-renewable resources to that of renewable resources in the energy and resources consumption of system. It can only reflect part of the environmental impacts on a complex ecosystem. The environmental pressure of a complex ecosystem not only lies in the resources composition (the resources and energy) consumed by the system, but also in the environmental impacts of all kinds of emissions discharged in the operating process of the complex ecosystem. However, ELR only reflects the former environmental impacts (Lan et al., 1998).

In order to take the benefit in the process of pollutant emission and trade exchange inside the system into consideration, Lu et al. have improved the ESIs by adding Emergy exchange ratio (EER) and EWI and put forward the new ESIs (Liu, 1999; Lu et al., 2003a,b). EER, representing the trade benefit, is added to the numerator, EYR; at the same time, EWI, representing the pollution degree, is added to the denominator. However, the ecological and economic benefits resulting from the circulating use of wastes, which is at the core of circular economy, are not taken into consideration in the industry complex ecosystem.

Most of the industry complex ecosystem cannot obtain free resources from the nature, neither renewable resources $(R)$ nor non-renewable $(\mathrm{N})$ resources. Purchasing with money from other producers is the most common way to obtain production resources. Therefore, in the expression with $\mathbf{R}$ or $\mathbf{N}$ as the denominator, when $\mathbf{R}$ or $\mathbf{N}$ equals to zero, the value of the expression is infinite. Though it is still an expression, the values calculated from the expression cannot be compared.

To overcome the limitations of the Emergy-based indices for assessing regional sustainability that was discussed above, we have modified the previous indices. Fig. 1 shows the relationships of Emergy from different sources in and out the industrial complex ecosystem. $\mathbf{R}$ and $\mathbf{N}$ refer to the Emergy of renewable and nonrenewable resources obtained directly from environment for free, respectively. $\mathbf{Y}$ stands for the final output Emergy. $\mathbf{N}_{\mathbf{1}}$ shows the Emergy of non-renewable resources bought from outside the systems. $\mathbf{R}_{\mathbf{1}}$ shows the Emergy of renewable resources bought from outside the systems. $\mathbf{C}_{\mathbf{1}}$ means the Emergy of waste and byproducts from outside the systems. $\mathbf{A}_{\mathbf{1}}$ means the Emergy of labor and investment, excluding $\mathbf{N}_{\mathbf{1}}, \mathbf{R}_{\mathbf{1}}$ and $\mathbf{C}_{\mathbf{1}}$. The sum of $\mathbf{N}_{\mathbf{1}}, \mathbf{R}_{\mathbf{1}}, \mathbf{C}_{\mathbf{1}}, \mathbf{A}_{\mathbf{1}}$ is the Feedback $(\mathbf{F})$ of the system according to the definition of Brown and Ulgiati. $\mathbf{W}$ refers to the Emergy of all kinds of pollutants discharged from the systems.

With the information of all kinds of emergies in Fig. 1, we are able to examine the sustainability of a given industrial complex 


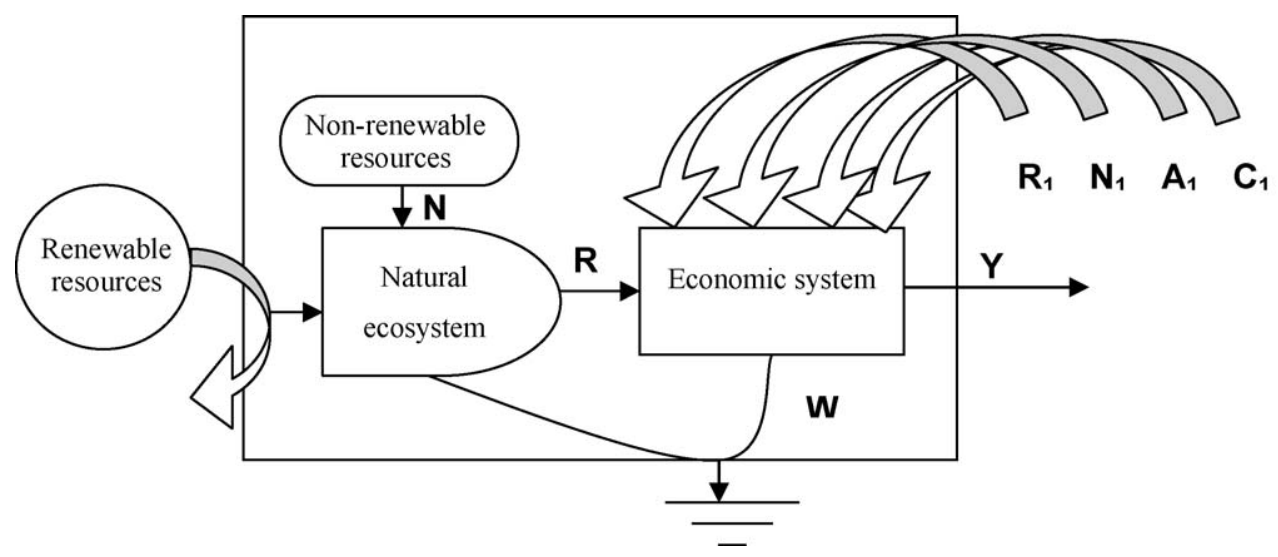

Fig. 1. Emergy analysis of industrial complex eco-system.

ecosystem by calculating the following indicators: CI (circular indices) refers to the circulation indices of system; WI (waste indices) refers to the pollution indices of system; BA (buyer advantage) refers to the benefit of buyers; SI (sustainability indices) refers to sustainability indices of system; ratio of Emergy to currency (sej/\$) refers to the ratio of total Emergy in a country or region in unit of time (per year) to its GDP; EMdollar refers to the amount of floating currency equivalent to the Emergy of a certain kind of resource or product; DP (dollar paid) refers to the amount of currency paid for certain kind of resource or product (in US dollars).

The expressions are shown in the following:

$\boldsymbol{Y}=\boldsymbol{N}+\mathrm{R}+\boldsymbol{N}_{\mathbf{1}}+\mathrm{R}_{\mathbf{1}}+\boldsymbol{A}_{\mathbf{1}}+\boldsymbol{C}_{\mathbf{1}}$

$\boldsymbol{C I}=1+\frac{\boldsymbol{C}_{\mathbf{1}}}{\boldsymbol{Y}}$

$\boldsymbol{W I}=\frac{\boldsymbol{W}}{\boldsymbol{Y}}$

EM dollar $=\frac{\boldsymbol{Y}}{\text { ratio of Emergy to currency }}$

$\boldsymbol{B} \boldsymbol{A}=\frac{\text { EM dollar }}{\boldsymbol{D P}}$

$\boldsymbol{S I}=\boldsymbol{C I} \times \frac{\boldsymbol{B} \boldsymbol{A}}{\mathbf{W I}}$

According to the definitions and expressions above, we can see that each concrete index and the integrated sustainability indices can reflect the ecological, economic and environmental benefits of a given industry complex ecosystem, which will be showed as the following:

$\mathbf{Y}$ refers to the total output of industry complex ecosystem and the total Emergy cost at the same time. It is not the case that the higher $\mathbf{Y}$ is, the healthier the industry complex ecosystem is. It mainly depends on efficiency.

CI refers to the ratio of wastes or by-products that can be circulated in the total output of the ecosystem. The higher $\mathbf{C I}$ is the better, under the precondition that there are feasible technology and reasonable economic benefit.

WI refers to the ratio of pollutant Emergy to total Emergy. The higher WI is the better. When there is no pollutant discharged from the system, $\mathbf{W}$ and $\mathbf{W I}$ tend to be zero and $\mathbf{S I}$ tends to be infinite.

BA refers to the real interest obtained from the exchange process of system and the outside, representing the economic benefit of industry complex ecosystem. Higher BA indicates that we can get more Emergy with less cost.
SI is positively related to $\mathbf{C I}$ and $\mathbf{B A}$, but negatively related to $\mathbf{W I}$. The industry complex ecosystem is more sustainable when $\mathbf{C I}$ and BA are higher, while WI is lower, vice versa. According to expression (6), we can get the following expression:

$\boldsymbol{S I}=\boldsymbol{B} \boldsymbol{A} \times\left(\frac{1}{\boldsymbol{W I}}+\frac{\boldsymbol{C I}}{\boldsymbol{W}}\right)$

If we define CWR (circular-waste ratio) as the ratio of circular Emergy of the system to waste Emergy,

$C W R=\frac{C I}{W}$

SI can be expressed as

$\boldsymbol{S I}=\boldsymbol{B A} \times\left(\frac{1}{\boldsymbol{W I}}+\mathbf{C W R}\right)$

From expression (9), we can draw a conclusion that $\mathbf{S I}$ is also positively related to the reciprocals of $\mathbf{B A}, \mathbf{C W R}$ and $\mathbf{W I}$.

\section{The development of policy scenarios for China's paper industry}

As required for SEA, 5 possible policy scenarios have been developed for the Chinese paper industry for the year of 2020:

3.1 Baseline scenario: follow the development of current tendency, without any policy interventions;

3.2 Globalization scenario: in the context of globalization, encourage continuous dependence on the import of raw materials and products;

3.3 Fast growing wood scenario: maximize the use of the fast growing wood in China for raw material supply;

3.4 Circular economy scenario: according to the requirement of circular economy, make good use of waste paper and 'four remnants of forestry' to the maximum;

3.5 Function economy scenario: minimize the paper consumption by maximizing the use of electronic-paper.

Table 1 shows the consumption and the output of paper and cardboard, the quantity of pulp used for the production of paper and the corresponding raw material composition in 5 scenarios, respectively. Data on the consumption of paper and cardboard per capita in China are calculated based on their correlation with the GDP per capita since 1990s: consumption of PAC per capita $(\mathrm{kg})=8.9+0.003 \times$ GDP per capita. China aims to quadruple its per capita GDP by 2020 from 7,063 Yuan in 2000. Taking into account the natural growth rate of the population, $1.07 \%$, the total 
Table 1

Raw material composition for production of pulp in different scenarios by 2020.

\begin{tabular}{|c|c|c|c|c|c|c|c|c|c|c|c|c|}
\hline \multirow[t]{3}{*}{ Scenarios } & \multicolumn{6}{|l|}{2003} & \multicolumn{6}{|l|}{2020} \\
\hline & \multirow[b]{2}{*}{$Q$} & \multirow[b]{2}{*}{$P$} & \multicolumn{2}{|l|}{ Baseline } & \multicolumn{2}{|c|}{ Globalization } & \multicolumn{2}{|c|}{ Fast wood } & \multicolumn{2}{|c|}{ Circular economy } & \multicolumn{2}{|c|}{$\begin{array}{l}\text { Function } \\
\text { economy }\end{array}$} \\
\hline & & & $Q$ & $P$ & $Q$ & $P$ & $Q$ & $P$ & $Q$ & $P$ & $Q$ & $P$ \\
\hline Consumption of PAC & 4806 & & 13,187 & & 13,187 & & 13,187 & & 13,187 & & 4806 & \\
\hline Import of PAC & 635 & & 1660 & & 2000 & & 2000 & & 2000 & & 635 & \\
\hline Export of PAC & 129 & & 272 & & 612 & & 612 & & 612 & & 129 & \\
\hline Output of PAC & 4300 & & 11,799 & & 11,799 & & 11,799 & & 11,799 & & 4300 & \\
\hline Quantity of paper pulp & 3910 & & 10,973 & & 10,973 & & 10,973 & & 10,973 & & 3910 & \\
\hline 1.Wood pulp & 820 & 21 & 2301 & 21 & 4060 & 37 & 6500 & 59.2 & 3498 & 31.9 & 1507 & 38.5 \\
\hline Domestic inputs & 217 & 5.5 & 609 & 5.5 & 1060 & 9.7 & 5000 & 45.6 & 2498 & 22.8 & 1507 & 38.5 \\
\hline Imported inputs & 603 & 15.4 & 1692 & 15.4 & 3000 & 27.3 & 1500 & 13.7 & 1000 & 9.1 & & \\
\hline 2.Non-wood pulp & 1170 & 29.9 & 3284 & 29.9 & 878 & 8 & 1200 & 10.9 & 1200 & 10.9 & & \\
\hline Grass pulp & 978 & 25 & 2743 & 25 & 200 & 1.8 & 200 & 1.8 & 200 & 1.8 & & \\
\hline 3.Pulp from waste paper & 1920 & 49.1 & 5388 & 49.1 & 6035 & 55 & 3273 & 29.8 & 6275 & 57.2 & 2403 & 61.5 \\
\hline Domestic inputs & 1170 & 29.9 & 3284 & 29.9 & 2035 & 18.5 & 3273 & 29.8 & 5275 & 48.1 & 2403 & 61.5 \\
\hline Imported inputs & 750 & 19.2 & 2105 & 19.2 & 4000 & 36.5 & & & 1000 & 9.1 & & \\
\hline
\end{tabular}

Note: PAC means paper and cardboard; $Q$ means quantity (unit: $10^{4}$ tons); $P$ means proportion (unit: \%).

consumption by 2020 will be 131.87 million tons. Material inputs for various kinds of pulp production are calculated according to the current technical standards. Different ratios of pulp are applied in different scenarios.

\section{Emergy-based sustainability assessment of the policy scenarios for China's paper industry}

Based on the previous research results of Emergy conversion ratio, we first calculated $\mathbf{R}_{\mathbf{1}}, \mathbf{N}_{\mathbf{1}}, \mathbf{C}_{\mathbf{1}}, \mathbf{A}_{\mathbf{1}}, \mathbf{W}$ of a ton of wood pulp, grass pulp, waste paper pulp and "four remnants pulp", respectively (Huang and Odum, 1991; Odum, 1996). Then, according to the total quantity and composition of pulp required in each policy scenario, we calculated $\mathbf{R}_{\mathbf{1}}, \mathbf{N}_{\mathbf{1}}, \mathbf{C}_{\mathbf{1}}, \mathbf{A}_{\mathbf{1}}, \mathbf{W}$ as well as $\mathbf{C I}$, BA, WI, CWR and SI of each policy scenario.

Table 2 shows the Emergy assessment results of each policy scenario according to the concepts and expressions discussed above.

As to $\mathbf{C I}$, globalization scenario has the highest $\mathbf{C I}$ (1.459) as a result of the import of a large amount of waste paper for pulp production. The fast growing wood scenario has the lowest CI (1.251) due to the consumption of great amount of log to produce wood pulp. In between, CIs of function economy scenario, baseline scenario and circular economy scenario are 1.450, 1.423 and 1.417, respectively.

Accordingly, there is similar characteristic and trend in CWR: the globalization scenario has the highest value of 9.79; fast wood scenario has the lowest value of 3.33 , the CWR of function economy scenario, circular economy scenario and baseline scenario are 8.87, 7.34 and 5.88 respectively. From CWR, the advantages of circular economy scenario in comparison with baseline scenario are self-evident.

As to $\mathbf{B A}$, the globalization scenario has the highest $\mathbf{B A}(2.74)$ due to the import of large amount of waste paper pulp. In comparison, fast wood scenario has the lowest BA (1.71) due to its dependence on the domestic wood production. The BA of function economy scenario, baseline scenario and circular economy scenario are $2.61,2.56$ and 2.44 , respectively.

The WI of globalization scenario is the lowest (0.047), because it has the higher ratio of waste paper pulp and the least pollutant emissions. The WI of the fast wood scenario is the highest (0.076), because it has a lower ratio of waste paper pulp and the most pollutant emissions.

As far as the comprehensive assessment indices, SI, is concerned, the globalization policy scenario has the highest score (85.4); while the policy in the fast wood scenario has the lowest score (28.38), only accounting for $1 / 3$ of that in the globalization scenario. The reason why the globalization scenario gets the highest score is that this strategy makes the best use of the resources from international markets. Of the 79.73 million tons of paper pulp produced domestically, 60.35 million tons is made of waste paper, accounting for $75.7 \%$ of the total. In the pulp-making schemes, using waste paper to make pulp is the most sustainable way, with the most economic and ecological benefits. On the one hand, globalization scenario needs to import a large amount of wood pulp and waste paper, which may mitigate the ecological and

Table 2

Comprehensive assessments on Chinese paper industry policy scenarios.

\begin{tabular}{|c|c|c|c|c|c|}
\hline Indices & Baseline & Globalization & Fast wood & Circular economy & Function economy \\
\hline $\mathbf{R}_{\mathbf{1}}$ & $1.88 \mathrm{E}+18$ & $2.18 \mathrm{E}+18$ & $7.96 \mathrm{E}+18$ & $3.11 \mathrm{E}+18$ & $3.85 \mathrm{E}+17$ \\
\hline $\mathbf{N}_{1}$ & $4.01 \mathrm{E}+18$ & $3.94 \mathrm{E}+18$ & $4.69 \mathrm{E}+18$ & $5.12 \mathrm{E}+18$ & $2.03 \mathrm{E}+18$ \\
\hline$A_{1}$ & $3.10 \mathrm{E}+19$ & $2.88 E+19$ & $3.57 \mathrm{E}+19$ & $3.75 E+19$ & $1.42 \mathrm{E}+19$ \\
\hline$C_{1}$ & $2.70 \mathrm{E}+19$ & $2.96 \mathrm{E}+19$ & $1.62 \mathrm{E}+19$ & $3.27 \mathrm{E}+19$ & $1.36 \mathrm{E}+19$ \\
\hline $\mathbf{Y}$ & $6.40 \mathrm{E}+19$ & $6.46 \mathrm{E}+19$ & $6.46 \mathrm{E}+19$ & $7.84 \mathrm{E}+19$ & $3.02 \mathrm{E}+19$ \\
\hline $\mathbf{W}$ & $4.60 \mathrm{E}+18$ & $3.03 E+18$ & $4.88 \mathrm{E}+18$ & $4.45 \mathrm{E}+18$ & $1.53 \mathrm{E}+18$ \\
\hline DP & $2.87 \mathrm{E}+06$ & $2.70 \mathrm{E}+06$ & $4.34 \mathrm{E}+06$ & $3.70 \mathrm{E}+06$ & $1.33 \mathrm{E}+06$ \\
\hline CI & 1.423 & 1.459 & 1.251 & 1.417 & 1.450 \\
\hline WI & 0.072 & 0.047 & 0.076 & 0.057 & 0.051 \\
\hline EMD & $7.35 \mathrm{E}+06$ & $7.42 \mathrm{E}+06$ & $7.43 E+06$ & $9.01 \mathrm{E}+06$ & $3.47 \mathrm{E}+06$ \\
\hline BA & 2.56 & 2.74 & 1.71 & 2.44 & 2.61 \\
\hline CWR & 5.88 & 9.79 & 3.33 & 7.34 & 8.87 \\
\hline 1/WI & 13.90 & 21.33 & 13.24 & 17.61 & 19.70 \\
\hline SI & 50.59 & 85.40 & 28.38 & 60.81 & 74.68 \\
\hline
\end{tabular}


environmental pressure of China; on the other hand, globalization scenario is based on the most advanced paper pulp making technology of foreign countries, with less environmental pollution and higher resource use efficiency, thus bringing the best economic and social benefits.

The unification of forestry and paper industry has been advocated and encouraged by the Chinese government. In this scenario, the development goal of fast wood is to supply 50 million tons wood pulp, accounting for $52.8 \%$ of the total 94.73 million tons of pulp. However, purchasers of wood pulp can only obtain a benefit 1.17 times of their costs, indicating that the tax on forest products is too high to make China competitive. The price of $1 \mathrm{~m}^{3}$ wood of China is 15-35 US dollars higher than that of international market. Thus, the cost of making wood pulp in China is $15.22 \%$ higher than the equivalent of international market. Therefore, in the comprehensive Emergy assessment, the score of wood pulp is only higher than grass pulp, obviously lower than the "four remnants" pulp and waste paper pulp. In the future when the policy obstacle is removed, the wood cost in China will be in accordance with the international wood cost and this situation will be improved. By doing so, in the scenario of unification of forestry and papermaking industry, the benefit of wood pulp purchasers will increase slightly by 1.71 times of their cost. However, this scenario still has the lowest score in the 5 scenarios. In addition, the waste cannot be reused actively; circular indices is also the lowest (1.251), only half of the highest indices. The waste indices of the scenario is the highest, another contributor to the lowest score in the comprehensive assessment.

The score of function economy (74.68) is only less than that of globalization scenario by 10.72 . That is because 24.03 million tons of paper pulp is made of waste paper pulp, accounting for $61.4 \%$ of the total 39.10 million tons pulp. The rest of the 1507 million tons of pulp is made of the "four remnants". The waste paper pulp is very good in both economic and ecological aspects, and the "four remnants" have high score in the comprehensive assessment.

Circular economy scenario is not very good in the assessment, with a score only higher than that of baseline scenario by 10.22 . That means that more policy incentives need be in place to increase the quantity of waste paper pulp used. In the circular economy scenario, only non-wood pulp is replaced by wood pulp. Therefore, both the baseline scenario and circular economy scenario have no obvious economic and ecological benefits.

\section{Conclusions}

Given the current consumption level of the paper and cardboard as well as the growth rate, by 2020 , the consumption of paper products per capita will be $93 \mathrm{~kg}$ and the national total consumption will reach 131.87 million tons, which exceeds greatly the current quantity in the United States (108 million tons) and Europe (110 million tons). This makes China, the United States and Europe the top three consumers of paper products in the world, which will impose great pressure on China's environment. The Emergy-based SEA on China's paper industry policy scenarios concludes the following:

5.1 The baseline scenario cannot improve the industry structure, which results into low development level and serious environmental pollution. In this scenario, 54.57 million tons of paper, cardboard, paper pulp and waste paper need to be imported. According to the constant price of 2003, additional 20.4 billion US dollars are required.

5.2 The globalization scenario has the highest score in comprehensive sustainability assessment. Under the precondition that we are able to maintain sufficient supply of paper products by benefiting both domestic and international markets, the globalization scenario is the most economical one. However, it is challenging to make this work.

5.3 Globalization scenario needs a large amount of foreign exchange. In this scenario, 90 million tons of paper, cardboard, pulp and waste paper should be imported in 2020. According to the constant price of 2003, additional 33.7 billion US dollars is needed. In 2003, the import of paper and cardboard cost 8.322 billion US dollars, only accounting for $1.6 \%$ of China foreign exchange storage ( 515.4 billion US dollars) in October 2004 Therefore, in 2020, China will be able to afford the import of paper and relevant products.

5.4 The scenario of unification of forestry and papermaking industry is not as perfect as most experts and national relevant departments expected. The implementation of this scenario requires reforms on the current national financial and tax regulations. We should learn from the precious experience and lesson in the fast wood cultivation from South America and Southeast Asia.

5.5 The implementation of the circular economy scenario needs scientific management and technical innovation. A scientific technical scheme and clear economic benefits are two prerequisites for operation.

5.6 A function economy is the essential way to resolve the problem of ever increasing paper products consumption at global scale in the future. From the function economy perspective, we must develop new products to substitute for paper, electronic paper for instance.

These conclusions make it clear that there is no optimal scenario for the paper industry in China. Policies need be coordinated to achieve higher waste paper recycling rate as promoted within the circular economy strategy and to facilitate the transition from product economy to function economy as the ultimate goal. In the mean time, efforts to maximize the economic and ecological benefits, enabling measures to reach the goals of the policy "unification of forestry and papermaking industry" should be introduced and the opportunities provided by globalization should be taken.

The case of China's paper industry shows that the Emergybased approach and the modified indices are suitable for assessing the sustainability of industry complex ecosystem. It is feasible to apply this approach in SEA of policy scenarios. Access to reliable data and information is crucial for the validity of the assessment.

\section{Acknowledgements}

This study was sponsored by the key project (No. 70433001, 70873121, 70573106) of National Natural Science Foundation of China, the National Basic Research Program of China (2005CB724206), the Knowledge Innovation Project of the Chinese Academy of Sciences (KZCX2-YW-324, KZCX2-YW-422), and the Key Supporting Project of the Ministry of Science and Technology of China (2007BAC28B04). This work was also partially supported by the State Key Laboratory of Urban \& Regional Ecology.

\section{References}

Appiah, O.S., 2001. Environmental impact assessment in developing countries: the case of Ghana. Environmental Impact Assessment Review 21, 59-71.

Brown, M.T., Ulgiati, S., 1997. Emergy-based indices and rations to evaluate sustainability: monitoring economies and technology toward environmentally sound innovation. Ecological Engineering 9, 51-69.

Cai, X.M. 2000. Ecosystem Ecology (in Chinese). Science Press, Beijing, pp. 194-200.

Hau, J.L., Bakshi, B.R., 2004. Promise and problems of Emergy analysis. Ecological Modelling 178, 215-225.

Huang, S.l., Odum, H.T., 1991. Ecology and economy: emergy synthesis and public policy in Taiwan. Journal of Environmental Management 32, 313-333.

Huang, C., Jennifer, Y., 2005. Cynthia Huang and Jennifer Yang. Importance of SEA in China - The Case of Three Gorges Dam Project. In: Schmidt, M., Elsa João, E. 
Albrecht, E. (Eds.), Implementing Strategic Environmental Assessment. Springer, pp. 331-345.

Hu, D., Wang, R.S., Lei, K.P., Li, F., Wang, Z., Wang, B.N., 2009. Expanding ecological appropriation approach: solar space method and a case study in Yangzhou city, East China. Ecological Complexity 6, 473-483.

Lan, S.F., Odum, H.T., Liu, X.M., 1998. Energy flow and Emergy analysis of the agroecosystems of China. Ecologic Science 17, 32-39.

Li, C.S., Fu, X.F., Zheng, D., 2001. Emergy analysis for evaluating sustainability of Chinese economy. The Journal of Natural Resources 16, 297-304 in Chinese.

Li, D., Wang, R.S., 2009. Hybrid Emergy-LCA (HEML) based metabolic evaluation of urban residential areas: the case of Beijing, China. Ecological Complexity 6, 484-493.

Li, H.T., Liao, Y.C., Yan, M.C., Hu, D., 2003a. Emergy evaluation and assessment of sustainability on the eco-economic system of Xinjiang. Journal of Geographical Sciences 58, 765-772 in Chinese.

Li, J.L., Xu, J.Q., Zhang, Z.L., 2003b. Energy based analysis on developmental situation and sustainable development countermeasure of Jiangsu ecology-economic system (In Chinese). Economic Geography 23, 615-620.

Li, Z.B., 2000. Evaluation of urban land sustainable use. Journal of Zhejiang Normal University (Natural Sciences) 23, 68-73 in Chinese.

Liu, Y.L., 1999. Research on indices and methods of assessing sustainable development of China. Ecological Economy 6, 17-20 in Chinese.

Lu, H.F., Ye, Z., Zhao, X.F., Peng, S.L., 2003a. A new Emergy indices for urban sustainable development. Acta Ecologica Sinica 23, 1363-1368 in Chinese.

Lu, H.F., Lan, S.F., Peng, S.L., 2003b. Extending study on energy indices for sustainable development. Environmental Science 24, 150-154 in Chinese.

Magelli, F., Boucher, K., Hsiaotao, T. Bi, Melin, S., Bonoli, A., 2009. An environmental impact assessment of exported wood pellets from Canada to Europe. Biomass \& Bioenergy 33, 434-441.
Momtaz, S., 2002. Environmental impact assessment in Bangladesh: a critical review. Environmental Impact Assessment Review 22, 163-179.

Say, N.P., Yucel, M., 2006. Strategic environmental assessment and national development plans in Turkey: Towards legal framework and operational procedure. Environmental Impact Assessment Review 26, 301-316.

Odum, H.T., 1996. Environmental accounting: Emergy and decision making. John Wiley \& Sons Inc., New York, pp. 8.

Sui, C.H., Zhang, Y.H., Lan, S.F., 1999. Emergy evaluation of environment economic system. Chongqing Environmental Science 21, 18-21 in Chinese.

Sui, C.H., Lan, S.F., 2001. Principle and measure of urban ecosystem EMA. Chongqing Environmental Science 23, 4-6 in Chinese.

Wang, Y., Morgan, R.K., Cashmore, M., 2003. Environmental impact assessment of projects in the People's Republic of China: new law, old problems. Environmental Impact Assessment Review 22, 543-579.

Wang, R.S., 2003. Complex ecosystem and circular economy (in Chinese). Meteorological Press, Beijing, pp. 3-16.

Yan, M.C., Odum, H.T., 1998. A study on Emergy evaluation and sustainable development of Tibetan eco-economic system. Journal of Natural Resources 13, 116-125 in Chinese.

Yang, Y.X., Cai, Y.L., 2000. Evaluation on Chinese countryside sustainable development: SEEA method and its application. In: Natural Geography Committee of the Geographical Society of China (Eds.), Research on regional response to global change. People's Education Press, Beijing, in Chinese, pp. 181-195.

Zhang, Y.H., Lan, S.F., Chen, F.P., 1998. Emergy analysis for resources, environment and sustainable development of Hainan Province. Ecologic Science 17, 121-212 in Chinese.

Zhu, D., Ru, J., 2008. Strategic environmental assessment in China: motivations, politics, and effectiveness. Journal of Environmental Management 88, 615-626. 